\title{
Modeling, analysis and development of "hybrid" manual and solar PV based power generation system
}

\author{
Mohd. Tariq ${ }^{1, *}$, Khyzer Shamsi², Tabrez Akhtar ${ }^{3}$ \\ ${ }^{1}$ M.Tech Student, Department of Electrical Engineering, Indian Institute of Technology, Kharagpur, India \\ ${ }^{2}$ Protection design engineer, Al Jazirah Engineers and consultants, Al-khobar, Kingdom of Saudi Arabia \\ ${ }^{3}$ Assistant Manager, Delhi Metro Rail Corporation Ltd., Delhi, India
}

\section{Email address:}

tariq.iitkgp@gmail.com (M. Tariq)

\section{To cite this article:}

Mohd. Tariq, Khyzer Shamsi, Tabrez Akhtar. Modeling, Analysis and Development of "Hybrid" Manual and Solar PV Based Power Generation System, American Journal of Electrical Power and Energy Systems. Vol. 2, No. 2, 2013, pp. 44-49.

doi:10.11648/j.epes.20130202.13

\begin{abstract}
This paper presents the analysis \& development of hybrid Manual and Solar PV Based Power Generation System as there is a requirement to supply the rural areas of India and other developing countries with reliable electricity. Most of the rural areas won't have access to reliable electrical power even in the next ten years. Therefore alternate means of generating electrical energy will have to be utilized at local level. One such alternative is to produce electrical energy using hybrid systems utilizing manpower and solar energy. Local institutions like Panchayats might play an important role in the implementation, operation and maintenance of the proposed power generation system. The unregulated voltage generated by the proposed power generation system has been regulated with the help of electronic circuits.
\end{abstract}

Keywords: DC Generator, Prime Mover, Hybrid Power Generation, Solar PV, Voltage Regulator

\section{Introduction}

Most of the power generation in India is carried out by conventional energy sources, coal and mineral oil-based power plants which contribute heavily to greenhouse gases emission. Setting up of new power plants is inevitably dependent on import of highly volatile fossil fuels. Thus, it is essential to tackle the energy crisis through judicious utilization of abundant renewable energy resources, such as biomass energy, solar energy, wind energy, geothermal energy and Ocean energy. Last 25 years has been a period of exuberant hunt of activities related to research, development, production and demonstration at India. India has obtained application of a variety of renewable energy technologies for use in different sectors too.

Most of the rural areas of India don't have reliable access to electricity. The cost of installation and maintenance of transmission lines in these areas is quite high due to low population densities. Some of these areas won't have access to reliable electrical power even in the next ten years. Therefore alternate means of generating electrical energy will have to be utilized at local level. One such alternative is to produce electrical energy using Manual Charkha Based Power Generation System. [1]
India has abundant manpower. This can be utilised in the generation of electrical energy. A wheel coupled to an electric generator may be rotated to produce electricity. However, the revolutions per minute (r.p.m.) required by the generator prime-mover is quite high for obtaining the suitable at armature terminals. This problem can be solved by using a gear-system or by using wheels of different radii. However, the gear system leads to

considerable increase in weight of the apparatus. Hence, wheels of different radii are employed [1]. But this system has some limitations as it totally depends upon the manual resources. So for countries having lesser population density, this system /model will not work.

The solar radiation intensity is quite high in India for most of the year [2]. This energy can be harnessed for the generation of electrical energy. The main drawback of solar energy is that it is intermittent in nature. This drawback can be taken care of by using this in tandem with manual power as discussed above.

So, in this paper a Hybrid Manual and Solar PV based power generation system has been proposed to overcome the limitations of Manual \& Solar PV based systems installed individually.

This power generation system can be used to provide energy to light loads such as lighting, mobile charging, i- 
pod charging, charging of flashlights etc. However these equipments require constant voltages. Hence a constant voltage regulator will have to be used such as $78 \mathrm{XX}$.

Mobile-charger will require 7805 to obtain a constant voltage.

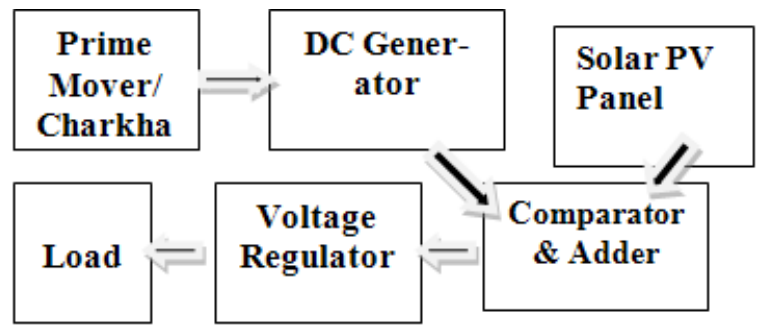

Figure 1. Block diagram of the Proposed Hybrid Power Generation System.

The two systems are coordinated such that they supplement each other. When the solar radiations are of low intensity and the power generated is not of desired value, we can run the generator at suitable speed such that the voltage obtained has the desired value and vice-versa.

Rural population constitutes $70 \%$ of India's population hence there is approximately 120 to 140 million families or households of which $30 \%-40 \%$ approximately is without electrification, from this it could be inferred that an enhanced living standards at $1 \mathrm{~kW} /$ household at 4 hours usage per day draws $105 \mathrm{MWh}$ per year/house hold which is over 250MW approximately for household consumption sector alone. [3]

The features of rural electricity viz, low and dispersed loads, high T \& D costs and seasonality of the load favors decentralized power plants for meeting rural electricity needs in a sustainable manner. Local institutions like Panchayats might play an important role in the implementation, operation and maintenance of the proposed power generation system. This will not only minimize transaction costs but also minimize transmission and distribution costs.[4]

\section{Manual Charkha Based Power Gen- eration}

A spinning wheel or charkha is a device for spinning thread or yarn from natural or synthetic fibers. The earliest clear illustrations of the spinning wheel come from Baghdad (drawn in 1237), China (1270) and Europe (1280), and there is evidence that spinning wheels had already come into use in both China and the Islamic world during the eleventh century. According to literature, the spinning wheel was introduced into India from Iran in the thirteenth century. The spinning wheel replaced the earlier method of hand spinning with a spindle. The first stage in mechanizing the process was mounting the spindle horizontally so it could be rotated by a cord encircling a large, hand-driven wheel. The great wheel is an example of this type, where the fiber is held in the left hand and the wheel slowly turned with the right. Holding the fiber at a slight angle to the spindle produced the necessary twist. The spun yarn was then wound onto the spindle by moving it so as to form a right angle with the spindle.

Hand powered spinning wheels are powered by the spinner turning a crank for fly wheel with their hand, as opposed to pressing pedals or using a mechanical engine. The table-top or floor charkha is one of the oldest known forms of the spinning wheel. The charkha works similarly to the great wheel, with a drive wheel being turned by hand, while the yarn is spun off the tip of the spindle.

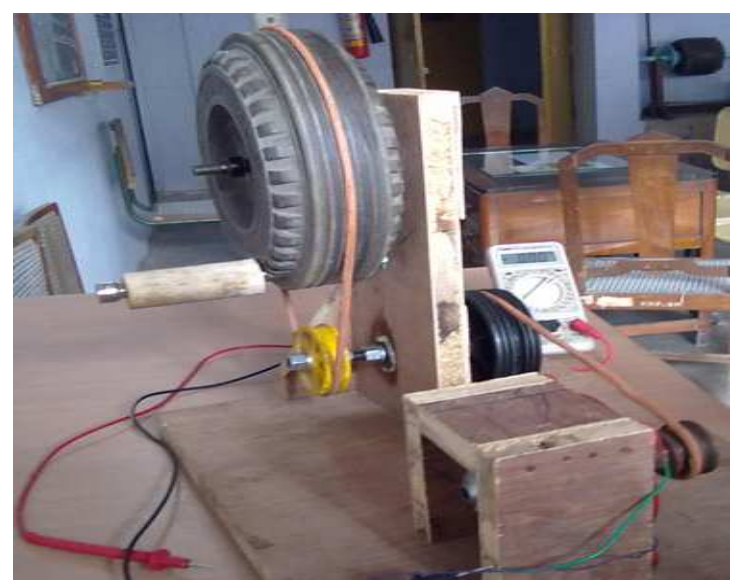

Figure 2. Model for Manual Charkha Based Power Generation System [1]

Table 1. RPM of Generator and output Voltage [1].

\begin{tabular}{ll}
\hline RPM of Generator & Output Voltage $(\mathbf{V})$ \\
\hline 645 & 5.00 \\
750 & 6.28 \\
775 & 6.50 \\
910 & 7.50 \\
950 & 7.85 \\
1030 & 8.00 \\
1105 & 8.55 \\
1193 & 9.00 \\
\hline
\end{tabular}

Observation Table of rpm of Generator and Output Voltage.

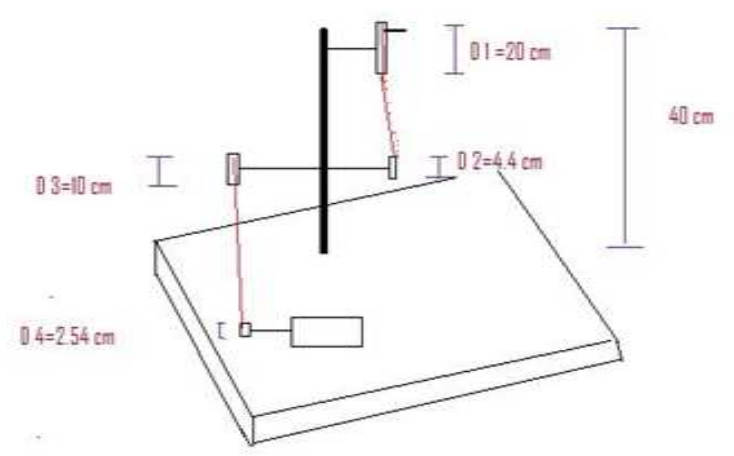

Figure 3. Diagrammatic Representation Of Multi-Wheel Charkha [1].

\section{Calculation of Various Radii}

D1- Diameter of wheel on which manual power is ap- 
plied

D2- Diameter of wheel directly below the handled wheel

D3- Diameter of wheel coupled with the second wheel

D4- Diameter of wheel attached with PM dc generator

N1- input mechanical rpm

N2- rpm of wheel having diameter D2

N3- rpm of wheel having diameter D3

N4- required rpm of PM dc generator

Because of same linear velocity

$$
\pi \mathrm{D} 4 * \mathrm{~N} 4=\pi \mathrm{D} 3 * \mathrm{~N} 3
$$

Hence, $\mathrm{N} 3=(\mathrm{D} 4 / \mathrm{D} 3) * \mathrm{~N} 4$

Our generator has $\mathrm{D} 4=2.4 \mathrm{~cm}$

For voltage $=7.5 \mathrm{~V}$, the reqd. $\mathrm{rpm}=910$

Therefore, $\mathrm{N} 3=2184 / \mathrm{D} 3$

Now, $\mathrm{N} 2=\mathrm{N} 3$

Hence,D1=2184 X (D2/D3)/N1

Assuming N1 $=50 \mathrm{rpm}$

$\mathrm{D} 1 \mathrm{D} 3 / \mathrm{D} 2=43.6 \mathrm{~cm}$

We choose,

$\mathrm{D} 1=20 \mathrm{~cm}, \mathrm{D} 2=4.6 \mathrm{~cm}, \mathrm{D} 3=10 \mathrm{~cm}$

\section{Solar PV Based Power Generation}

Solar energy is the most abundant, inexhaustible and clean of all the renewable energy resources till date. The power from sun intercepted by the earth is about $1.8 \times 1011$ MW, which is many times larger than the present rate of all the energy consumption. Photovoltaic technology is one of the finest ways to harness the solar power. A photovoltaic power generation system consists of multiple components like cells, mechanical and electrical connections and mountings and means of regulating and/or modifying the electrical output. These systems are rated in peak kilowatts $(\mathrm{kWp})$ which is an amount of electrical power that a system is expected to deliver when the sun is directly overhead on a clear day.[5]

The basic building block of PV technology is the solar cell. Many cells may be wired together to produce a PV module, and many modules are linked together to form a PV array. PV modules sold commercially has range in power output from about 10 watts to 300 watts, and produce a direct current. Commercial PV systems are about $7 \%$ to $17 \%$ efficient.

PV generators are neither constant voltage sources nor current sources but can be approximated as current generators with dependant voltage sources. During darkness, the solar cell is not an active device. It produces neither a current nor a voltage. However, if it is connected to an external supply (large voltage) it generates a current $I_{d}$, called diode current or dark current. The diode determines the i-v characteristics of the cell. There are three different models of pv cells generally available. The model consists of a current source ( Isc ), a diode (D), and a series resistance (Rs) [6]. The equivalent circuit of a PV cell is demonstrated below.

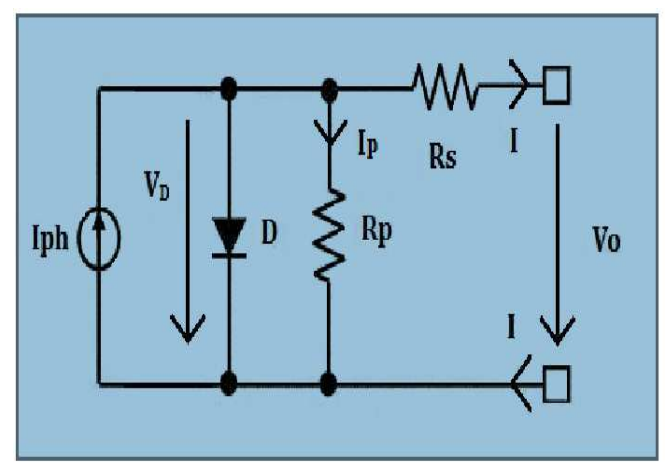

Figure 4. Equivalent circuit of a PV cell.

Derived from Kirchhoff's first law (also referred to as Kirchhoff's current law), the outputcurrent is given by:

$$
\begin{gathered}
I=I p h-I D-I p \\
I=I p h-I \text { sat }\left(\exp \frac{\text { q. }\left(V_{o}+I . R_{s}\right)}{n \cdot K \cdot T_{\text {cell. }} N_{s}}-1\right)-\frac{V_{o}+I . R_{s}}{R_{p}}
\end{gathered}
$$

where

I Output current

IphPhoto current

IsatDiode reverse saturation voltage

VoOutput Voltage

Rs Series resistance (Representing voltage loss on the way to external connectors)

RpParallel resistance (Representing leakage currents)

kBoltzmann's constant

q Charge on electron

Ns Number of cells in series

$\mathrm{N}$ Ideality factor

TcellSolar panel temperature

\section{Characteristic of the Photovoltaic Array}

The current generated in the solar cell by the current source (Iph) is proportional to the amount of light falling on it. When there is no load connected to the output Vo almost all of the generated current flows through diode D. The resistors $\mathrm{R}$ and $\mathrm{Rp}$ represent small losses due to the connections and leakage respectively. There is very little change in Voc for most instances of load current. However, if a load is connected to the output then the load current draws current away from the diode D. As the load current increases more and more current is diverted away from the diode D. So, as the output load varies so too does the output current, while the output voltage Voc remains largely constant. That is until so much current is being drawn by the load that diode D becomes insufficiently biased and the voltage across it diminishes with increasing load. Hence a number of observations are taken at different insolation levels. These observations are tabulated below in different tables. This results in an $\mathrm{I}-\mathrm{V}$ characteristic as shown in Figure 5. 


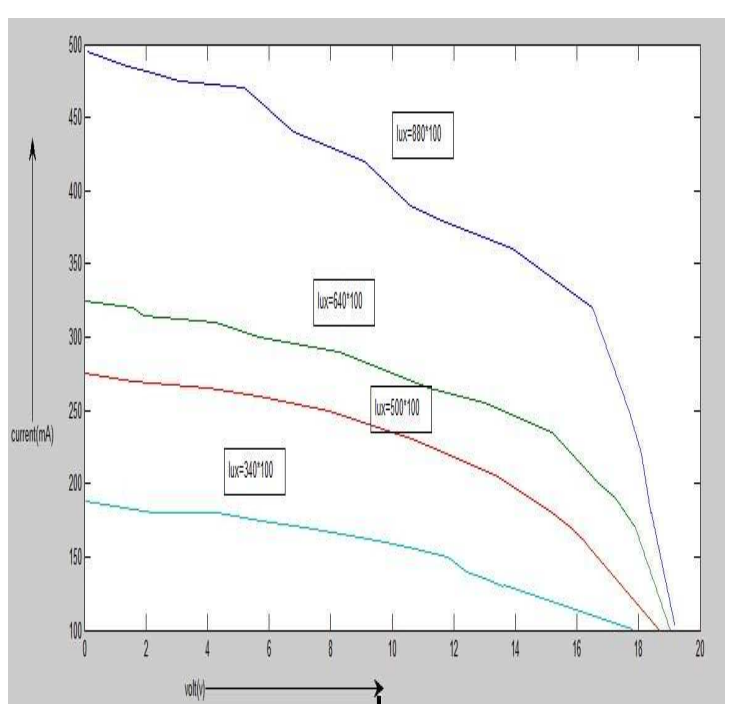

Figure 4. I-V Characteristic of A Photovoltaic Cell.

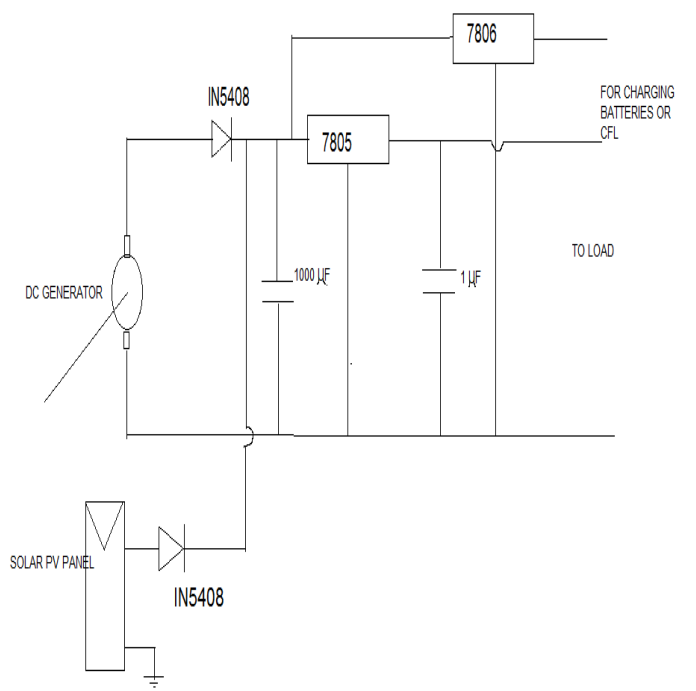

Figure 5. Circuit Diagram of Proposed Hybrid Power Generation System.

For Insolation $=340 \times 10^{2}$ lux

\begin{tabular}{lll}
\hline Voltage (V) & Current (mA) & Power (W) \\
\hline 2.22 & 180 & 0.39 \\
4.30 & 180 & 0.77 \\
5.75 & 175 & 1.01 \\
7.14 & 170 & 1.21 \\
8.36 & 165 & 1.38 \\
9.76 & 160 & 1.56 \\
10.74 & 155 & 1.66 \\
11.80 & 150 & 1.77 \\
12.40 & 140 & 1.74 \\
13.00 & 135 & 1.72 \\
13.59 & 130 & 1.71 \\
\hline
\end{tabular}

For Insolation $=500 \times 10^{2}$ lux

\begin{tabular}{lll}
\hline Voltage (V) & Current (mA) & Power (W) \\
\hline 0.01 & 275 & 0.00275 \\
1.59 & 270 & 0.43 \\
4.03 & 265 & 1.07 \\
5.15 & 260 & 1.47 \\
7.96 & 250 & 1.99 \\
10.63 & 230 & 2.44 \\
11.77 & 220 & 2.59 \\
13.43 & 205 & 2.75 \\
14.46 & 190 & 2.75 \\
15.20 & 180 & 2.74 \\
15.79 & 170 & 2.68 \\
\hline
\end{tabular}

Table 2. Voltage, current and power at different insolations.

For Insolation $=640 \times 10^{2}$ lux

\begin{tabular}{lll}
\hline Voltage (V) & Current $(\mathbf{m A})$ & Power $(\mathbf{W})$ \\
\hline 1.58 & 325 & 0.0065 \\
1.58 & 320 & 0.50 \\
4.26 & 310 & 1.72 \\
4.58 & 300 & 1.70 \\
8.28 & 290 & 2.40 \\
11.20 & 265 & 2.97 \\
13.00 & 255 & 3.32 \\
15.20 & 235 & 3.57 \\
16.70 & 200 & 3.34 \\
17.25 & 190 & 3.28 \\
17.90 & 170 & 3.046 \\
\hline
\end{tabular}

For Insolation $=800 \times 10^{2}$ lux

\begin{tabular}{lll}
\hline Voltage (V) & Current (mA) & Power (W) \\
\hline 0.1 & 485 & 0.48 \\
1.4 & 480 & 0.67 \\
2.2 & 475 & 1.05 \\
3.1 & 470 & 1.46 \\
5.20 & 440 & 2.23 \\
6.8 & 420 & 2.86 \\
9.1 & 390 & 3.55 \\
10.6 & 380 & 4.03 \\
11.6 & 360 & 4.18 \\
13.9 & 320 & 4.45 \\
15.5 & 250 & 4.13 \\
\hline
\end{tabular}




\section{Hybrid Power Generation}

Hybrid power generation system combines a renewable energy.

Source (PV in this case) with other forms of generation, usually a conventional generator powered by diesel or even another renewable form of energy like wind. Such hybrid systems serve to reduce the consumption of non renewable fuel. Barton et al. described a novel method of modelling an energy store used to match the power output from a wind turbine and a solar PV array to a varying electrical load and validated the method against time-stepping methods showing good agreement over a wide range of store power ratings, store efficiencies, wind turbine capacities and solar PV capacities [7]. Katti and Khedkar investigated the application of wind alone, solar-alone, and integrated wind PV generation for utilization as stand-alone generating systems, to be used at the remote areas which was based on the site matching and an energy flow strategy that satisfies the need with optimum unit sizing [8].

The small scale power generation suitable for home purposes has already been discussed in several papers. Bond et al. described current experience and trials in East Timor with solar photovoltaic (PV) technology by introduction of solar home systems (SHS) [9]. Posorski et al. proposed SolarHomeSystems (SHS) that are commercially disseminated and used them cost efficiently to substitute kerosene and dry cell batteries to reduce GHG emissions and thus make a significant contribution to climate protection [10].

Most of the hybrid power generation depends upon Solar with wind or diesel, but in this paper a novel generation system is proposed. Although the solar PV component is providing the sufficient power required for charging the mobile battery or lightning of the lamps, but it has one serious drawback. The sun does not shine all the time. One can collect it only during the day. Also the intensity of solar radiation is quite low in cloudy weather. It further depends on the climate conditions i.e. the solar insolation level varies seasonally. The implication is that power is needed all the time, but the sun and hence, solar energy, is not always available. Therefore, one can say that solar energy is intermittent in nature. So, one cannot totally rely on it. But the solar energy resource is enormous. Solar panels have numerous benefits for the environment. Even if there are some disadvantages of using these systems, the advantages still outweighed them.

Therefore we need a hybrid power generation system which combines the advantages of manual and solar power generation system. When the solar energy is not sufficient to provide the required amount of power for the desired applications, we can generate power manually by the charkha. On the other hand, if the primary purpose of rotating the charkha (i.e. spinning yarn, etc.) ceases to exist, one can revert to solar PV system for providing energy.

Circuit Diagram of The Proposed Hybrid Power Generation System

Two sources of energy are employed here. They are PM
DC generator run by manual charkha and solar PV panel. The two diodes IN5408 diode are used to prevent the flow of current from one source of energy to another source of energy. For charging of mobile phone batteries we require $5 \mathrm{~V}$ supply while $6 \mathrm{~V}$ supply is required for lighting lamp. The voltage regulators provide the constant required voltage. Two capacitors of $1000 \mu \mathrm{F}$ and $1 \mu \mathrm{F}$ are used in the circuit.

\section{Conclusion}

The analysis and the experimental results of the proposed hybrid power generation system shows that this system can be effectively used in rural/remote areas for low power applications. The proposed system may be installed easily and economically in remote locations with the help of the local committees like panchayats etc. as the system exhibits high performance and low cost to be implemented. It is reliable, simple, and an excellent option to be employed for low power applications. Many countries have enormous manpower in rural areas, so this research is very significant. Though Solar PV cost is high but with the subsidies provided by the governments of several countries, this proposed hybrid power generation system can be of much use in rural areas.

\section{References}

[1] Mohd Tariq, Khyzer Shamsi \& Tabrez Akhtar, "Analysis, Modeling and Development of Manual Charkha Based Power Generation System",Energy and Environmental Engineering Journal, 2012 1(3),pp-108-111.

[2] B.H. Khan, "Non- Conventional Energy Sources", $2^{\text {nd }}$ Edition, Tata McGraw hill Pub. Co., 2009.

[3] United Nations. "Energy Services for Sustainable Development in Rural Areas in Asia and the Pacific: Policy and Practice”. New York: United Nations, 2005.

[4] Mohd Tariq \& Khyzer Shamsi "Application of RET to Develop educational infrastructure in Uttar Pradesh.”, International Journal of Recent Trend In engineering, ACEEE (USA), Vol.4 Nov.2010, pp 187-190.

[5] Bhubaneswari Paridaa, S. Iniyanb \& Ranko Goicc, "A review of solar photovoltaic technologies", Renewable and Sustainable Energy Reviews 15 (2011) 1625-1636.

[6] Abu Tariq, M. Asim, Mohd Tariq (2011) "Simulink based modeling, simulation and Performance Evaluation of an MPPT for maximum power generation on resistive load", 2nd International Conference on Environmental Science and Technology,Singapore.

[7] John PB, David GI. "A probabilistic method for calculating the usefulness of a store with finite energy capacity for smoothing electricity generation from wind and solar power". Journal of Power Sources 2006;162:943-8.

[8] Katti PK, Khedkar MK. "Alternative energy facilities based on site matching and generation unit sizing for remote area power supply". Renewable Energy 2007;32:1346-62. 
[9] Bond M, Fuller RJ, Lu Aye. "A policy proposal for the introduction of solar home systems in East Timor". Energy Policy 2007;35:6535-45.
10] Posorski R, Bussmann M, Menke C. "Does the use of Solar Home Systems (SHS) contribute to climate protection?" Renewable Energy 2003;28:1061-80. 